\title{
Allocation, incentives and distortions: the impact of EU ETS emissions allowance
}

\section{allocations to the electricity sector}

\author{
Karsten Neuhoff*, Kim Keats**, Misato Sato*
}

19 May 2006

\begin{abstract}
The allowance allocation under the European Emission trading schemes differs fundamentally from earlier cap and trade programs, like $\mathrm{SO}_{2}$ and $\mathrm{NOx}$ in the USA. Because of the iterative nature of negotiations of the overall budget, the allocation also has to follow an iterative process. If power generators anticipate that their current behaviour will affect future allowance allocation, then this can distort today's decisions. Furthermore, the National Allocation Plans (NAPs) contain multiple provisions dealing with existing installations, what happens to allocation when they close, and allocations to new entrants. We provide a framework to assess the economic incentives and distortions that provisions in NAPs can have on market prices, operation and investment decisions. To this end, we use both analytic models to illustrate the incentives effects and results from numerical simulation runs that estimate the magnitude of impacts from different allocation rules.
\end{abstract}

Keywords: Allowance allocation, Emission trading, Power sector, Economic incentives

JEL classification: D24, D92, Q28, L10

\footnotetext{
* Faculty of Economics, University of Cambridge, Sidgwick Avenue, Cambridge, CB3 9DE, UK. Contact Email: karsten.neuhoff@econ.cam.ac.uk. +44 1223 335290; Fax. +44 1223 335299, Financial support from the UK Research council project TSEC, and from Carbon Trust and Climate strategies is gratefully acknowledged.

** ICF Consulting, Egmont House, 25-31 Tavistock Place, London WC1H 9SU Contact Email : kkeats@icfconsulting.com +44 (0) 7712580 654; Fax: +44 (0) 2073914701
} 


\section{Introduction}

The 25 National Allocation Plans (NAPs) established autonomously by the EU Member States (MS) are central to the EU Emissions Trading Scheme (ETS). According to Articles 9 to 11 and Annex III of the ETS Directive ${ }^{1}$, NAPs must state how the total quantity of emissions allowances will be distributed to installations within their jurisdiction for each trading phase. The process of deciding the second phase allocation is currently underway. Each MS must submit their national allocation plans for 2008-2012 to the EU Commission by $30^{\text {th }}$ June 2006. Over the subsequent three months period, these will be assessed by the Commission according to criteria outlined in the Directive.

How to initially allocate allowances has long been a central issue in the debate on market-based instrument design. Since Montgomery put forward some thirty years ago that market efficiency would be independent of the initial allocation "modes" used to distribute tradable permits (Montgomery 1972), considerable advances have been made to further understanding of the implications of allocation to the functioning of the allowance market. Recent literature, primarily discussing allocation in the context of the $\mathrm{US} \mathrm{SO}_{2}$ and NOx programmes, evaluates different allocation modes using analytical, empirical and comparative approaches (Ellerman et al. 2000). This literature gives support for the argument that allocation indeed matters: the choice of allocation mode has distributional effects, but also consequences for efficiency and hence the overall costs of emissions abatement. (Burtraw et al. 2001; Burtraw et al. 2002). However, the EU ETS is a unique undertaking compared with the US programmes on several grounds. Addressing these differences is crucial when applying insights from the existing literature to

\footnotetext{
${ }^{1}$ Directive 2003/87/EC.
} 
allocation issues in the EU ETS. Three key differences in particular increase the complexity with the EU ETS.

Firstly, the EU Emissions Trading Scheme is by far the largest of its sort. Distributional considerations carry significant weight when giving away assets of such value to private sector agents. At $\mathrm{CO}_{2}$ prices of $€ 11 / \mathrm{t} \mathrm{CO}_{2}$, the annual value of emissions allowances reaches approximately $€ 24$ billion $^{2}$. By law, auctioning is likely to remain small ${ }^{3}$. Certain modes of free allowance allocation can create incentives of some significance for rational firms in a competitive market to adjust decisions on operation, investment and closure in order to influence future allocations.

Secondly, in most US programs allowances have been allocated at the beginning of the program, with a clear understanding that no subsequent allocation will take place. In sharp contrast to this 'one-off' allocation the EU ETS adopts a sequential approach. Allocation plans are decided for one commitment period at a time, with repeated negotiations about the allocation for the following period. Although consistent with the iterative nature of international emission reduction negotiations, this allocation approach can have significant implications to efficiency of the market compared with one-off allocation. For example, it creates perverse incentives for $\mathrm{CO}_{2}$ intensive plants to remain in operation in order to receive free-allocations, even if closure or replacement is socially more efficient. In addition, firms might invest in and operate more carbon intensive technologies if they anticipate that future allocations of allowances will be proportional

\footnotetext{
${ }^{2} 2.2$ billion tonnes of annual CO2 emissions in Phase I (Commission, 2005) at spot EUA price of €11/tCO2 in April 2006 (European Energy Exchange).

${ }^{3}$ A maximum of 5\% and 10\% of allowances may be auctioned in Phase I and II respectively under Articles 9 to 11 and Annex III of the ETS Directive. This gradual incorporation of auctioning is incoherent with the fact that private and equity ownership are considerably lower in the EU, hence EU citizens are more likely to object to freeallocation compared with US citizens.
} 
to today's emissions or output and fuel choice. This implies higher overall costs of emissions abatement.

Thirdly, further complications are introduced due to the heterogeneity among allocation methods adopted across Europe. The theoretical arguments for harmonization are strong (Ãhman et al. 2006). Under the current system where some discretion over NAPs is retained by each MS, we expect allocation rules will reflect national interest. For example, where the actions of a single MS is expected to have a small impact on the European $\mathrm{CO}_{2}$ price, national policies may be pursued with the objective of reducing impacts on domestic electricity prices. Pursuing the national objective can, however, have an adverse impact on $\mathrm{CO}_{2}$ emissions. If many countries set out to minimise electricity prices, increased demand for allowances pushes up prices in the EU ETS, increasing the overall costs of abatement for Europe. High $\mathrm{CO}_{2}$ prices, moreover, are likely to trigger some emission reductions among other market participants and increase use of international mechanisms (e.g. CDMs and JI).

The potential complexity of allocation plans has thus reached new heights with the EU ETS. The objective of this paper is to draw a clear set of messages to guide future allocations from our detailed analysis of the financial incentives resulting from the allocation process for power generators in liberalized electricity markets. Because of the key role the electricity sector plays in determining the $\mathrm{CO}_{2}$ price and ultimately on the success of the overall scheme (electricity represents around $60 \%$ of overall emissions regulated under the EU ETS), insights from this sectoral study have useful bearing on other carbon intensive sectors covered by the scheme. 
In this study, we use both analytic models to illustrate the incentives effects and results from numerical simulation runs that estimate the magnitude and the relative impacts of different allocation rules.

We do not assess strategic behaviour of generators in the electricity, gas or $\mathrm{CO}_{2}$ market (Newbery 2005) but assume a competitive market. Power dispatch simulations of Great Britain (England, Wales and Scotland) and all of Europe are solved for the reference baseline - using permanent grandfathering and auctioning allocation methods. The base-case results are compared to results from simulations of alternative allocation scenarios, to demonstrate numerically the extent to which allocation can distort operation, investment, electricity prices and $\mathrm{CO} 2$ emissions. We do caution that there is some debate as to whether dominant generation companies in some European countries are restrained not by the competition from existing companies or new entrants, but by the threat of triggering regulatory intervention. Such companies can develop prices that mimic the prices of competitive markets. However, the threat of windfall profit taxes, the anticipation of the impact of their current behaviour on the ongoing negotiations about allowance allocation for future periods, or the link to developments in other sectors of energy policy might induce such companies to refrain from adding opportunity costs of $\mathrm{CO}_{2}$ prices to the wholesale price level of electricity.

The remainder of this paper is structured as follows. In Section 2 we describe the reference case, which mimics the results of an efficient cap and trade program, and then discuss the distortions that result due to the allocation to existing power stations. Section 3 deals with new entrants. Section 4 sets out some conclusions. 


\section{Allocation to Incumbents}

For the Phase I trading period, incumbent firms received allowances based on their historic emissions. Most member states took some average over a three to five year period between 1990 and 2002. For future trading periods the Member States have to again define NAPs for the ETS. ${ }^{4}$ The commission and various member states announced that current behaviour will not be basis for future allocations, and it is indeed unlikely that behaviour post 2005 will be used for allocations in the period 2008-2012. It is however difficult for governments to commit to not redefining allocation methods and base periods in future. It is likely that the base period will be adjusted over time to reflect changes in distribution of plants over time. It is for example difficult to envisage that in 2011 a government will decide to allocate allowances to a power plant that closed down in 2003. This suggests that some element of 'updating' of allocation plans cannot be avoided if such plans are made sequentially.

A consistent methodology of allocating allowances is therefore likely to make allocation contingent on past activities of a plant. We show that such contingent allocation has detrimental impacts on the efficiency of emission trading, that vary with the specific allocation methodology. The incentives the allocation methodology creates for seperation of power plants has been extensively discussed (Bernard et al. 2001; Palmer and Burtraw 2003; Palmer and Burtraw 2004; Entec and NERA 2005; Keats and Neuhoff 2005). This section extends this discussion by addressing issues specific to the EU ETS.

${ }^{4}$ Defined by the Kyoto process (e.g. 2005-2007, 2008-2012) 


\subsection{The 'updating dilemma'}

We begin by presenting a theoretical framework for evaluating the impact of updating before moving on to quantify its impacts. To illustrate the effect of updating, consider a generation system with various technologies. In our auction base case, as the $\mathrm{CO}_{2}$ price increases, the generation portfolio will shift towards less carbon intensive power generation. The trace of the relationship between $\mathrm{CO}_{2}$ price and resulting $\mathrm{CO}_{2}$ emissions is referred to as the marginal abatement cost curve (MACC), as shown in Figure 1. With updating, the emitter receives some future allowances with today's emissions. The value of this future allocation will drive a wedge (indicated by the area labelled "future value") between the market price of $\mathrm{CO}_{2}$ allowances and the polluter's internal opportunity cost. This can be represented as an upward shift of the MACC. The $\mathrm{CO}_{2}$ market price must therefore rise to ensure the $\mathrm{CO}_{2}$ budget is not violated (See Boeringer and Lange, (2005)).

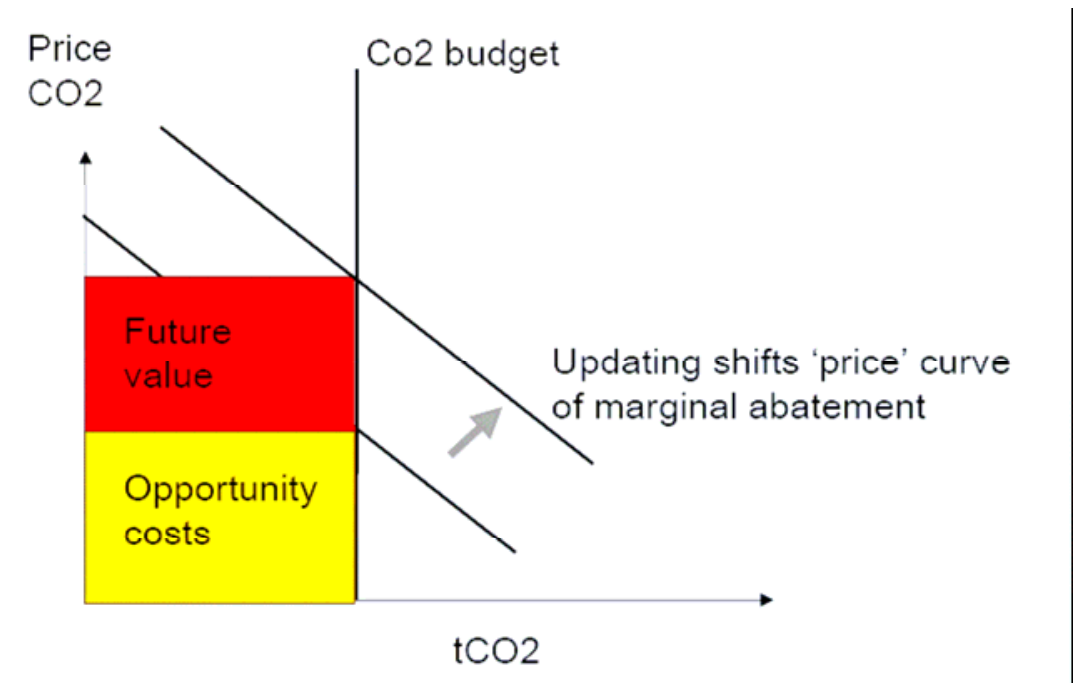

Figure 1 Impact of updating on marginal abatement cost curve 
From the perspective of one country, using policies that promise updating is a tempting option. Emissions from the country will have little effect on the ETS price. Yet by adding future value, updating essentially provides an output subsidy that reduces the variable cost of the economic activity. Thus national efforts to reduce economic activity and hence $\mathrm{CO}_{2}$ emissions are reduced. Updating can therefore have adverse effects on emission levels, for example, by biasing investments in carbon-intensive technologies (e.g. coal). Moreover, if the demand for electricity is price elastic, any resulting drop in electricity prices (Harrison and Radov 2002) could trigger higher electricity consumption, production, further increasing $\mathrm{CO}_{2}$ emissions.

This approach will also have consequences on neighbouring jurisdictions. Figure 2 illustrates a case with two countries. Each country is characterised by a marginal abatement cost curve and emission budget. Imagine that equilibrium prices coincide in both countries, even in the absence of trade at point $\mathrm{X}$. The right side of Figure 2 illustrates that with international trade the individual marginal abatement cost curves and the budgets are added, and obviously the same equilibrium price results.

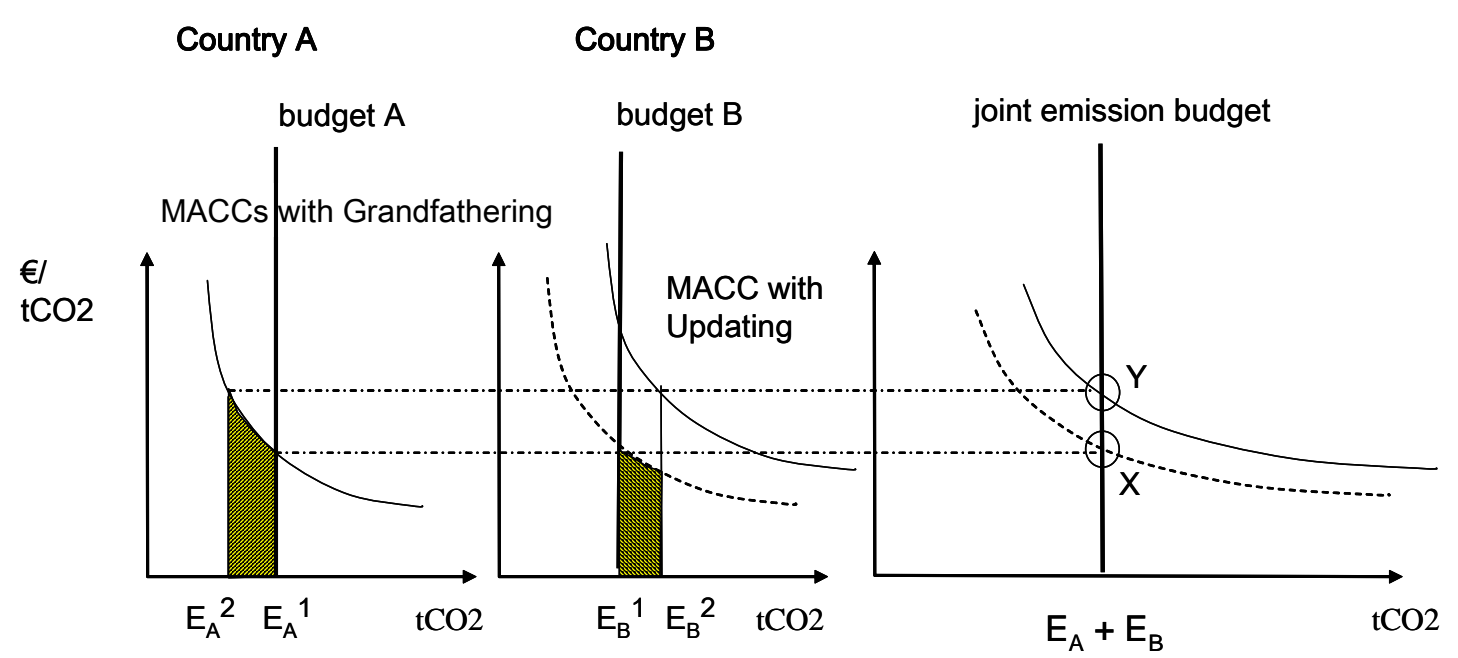

Figure 2 Impact of updating in a two-country emission trading system 
If one country, say Country B, employs updating, then a wedge is created between $\mathrm{CO}_{2}$ price and opportunity costs of $\mathrm{CO}_{2}$ emissions. As companies' opportunity cost of reducing $\mathrm{CO}_{2}$ emissions is not affected, the MACC has to shift upwards. When we allow trading of allowances between the two countries, the joint MACC also shifts upwards. The market now clears at the new equilibrium $\mathrm{Y}$ with higher $\mathrm{CO}_{2}$ prices. How this joint equilibrium is reflected in national output choices can be seen by moving along the dashed line from point $\mathrm{Y}$ to the left. The resulting $\mathrm{CO}_{2}$ price in Country A is higher and the country will implement additional $\mathrm{CO}_{2}$ emission reductions equal to $\mathrm{E}_{\mathrm{A}}{ }^{1}-\mathrm{E}_{\mathrm{A}}{ }^{2}$. The $\mathrm{CO}_{2}$ prices will also be higher in Country $\mathrm{B}$, but as the MACC has been shifted up even further, the country increases its emissions of $\mathrm{CO}_{2}$ by $\mathrm{E}_{\mathrm{B}}{ }^{2}-\mathrm{E}_{\mathrm{B}}{ }^{1}$. The global budget ensures that the total emission reductions are not affected. Comparing the shaded areas under the MACCs, it is clear that savings made in Country B are outweighed by the additional abatement costs incurred by Country A.

One might argue that Country B or its companies 'pay' for these additional abatement efforts of Country A. However in the process Country B introduces a wedge, reducing the marginal opportunity costs for its industry and consumers at the expense of higher 'international' $\mathrm{CO}_{2}$ price and thus higher marginal opportunity costs for foreign industry and consumers. This might be referred to as 'free-riding' on others' emissions reductions.

Ahman et al. (2006) recognise that individual Member States' decisions on NAPs affect the overall efficiency of the system, and also that a strong EU approval process of NAPs is required to limit distortions from heterogeneity of NAPs. In addition, the application of updating is not limited to cross-border distortions. Similar arguments can be made about allocation procedures that differ across sectors (see Keats and Neuhoff 2005). 
Acknowledging the problems associated with defining future allocations as a function of output levels in the past, some governments have declared that they will not allow the use of updating. For such announcements to be credible, however, governments must clearly outline what approach they envisage for future allocation.

\subsection{Quantifying impacts}

\subsubsection{Base case - auctioning or perfect grandfathering}

Various studies have modelled the impact of $\mathrm{CO}_{2}$ allowances on the European power sector (see for example Sijm et al, this issue). To quantify the impact of $\mathrm{CO}_{2}$ allowances on both the GB and the EU power sector we use ICF Consulting’s Integrated Planning Model (IPM®). It is a linear programming model that selects generating and investment options to meet overall electricity demand today and on an ongoing basis over the chosen planning horizon at minimum cost. For the GB simulations, England, Wales and Scotland are treated as an island with no electrical interconnection to its neighbours. In the European simulations, IPM is designed to replicate the operations of the interconnected European power system using an accurate engineering representation of power plants, transmission links and fuel supply options.

In order to calculate the distortions induced by the NAPs we have to define a reference or base case. In our base case we assume that all allowances are auctioned. This base case creates the same investment, operation and closure decisions as a one-off allocation of free allowances. ${ }^{5}$ The 'only’ difference between auctioning and permanently allocating allowances are the rents transferred from government to historic emitters. In this paper we do not discuss the mix of auctioning and free allocation required to compensate power companies for the effect of the $\mathrm{CO}_{2}$

\footnotetext{
${ }^{5}$ Most of the US cap and trade programs for $\mathrm{SO}_{2}$ and NOx used such a one-off allocation. Given the larger value of CO2 allowances, the novel experience with a $\mathrm{CO} 2$ trading scheme and the iterative nature of the definition of national or regional targets such a permanent allocation was not viable under the ETS.
} 
emission trading scheme (see Keats and Neuhoff 2005). This does not apply to companies in regulated market environments or in situations where companies are exposed to regulatory threats, e.g. windfall profits. In the extreme case of pure auctions, companies will face the full costs and can pass these on. With complete free allocation there is little impact on their average costs and thus on prices (Burtraw et al. 2005). Results for the auctioning case and the no $\mathrm{CO}_{2}$ case are shown in Figure 3.

(a) CO2 Emissions (MMTonnes)

(b) Baseload Electricity Price (€ 2005/MWh)
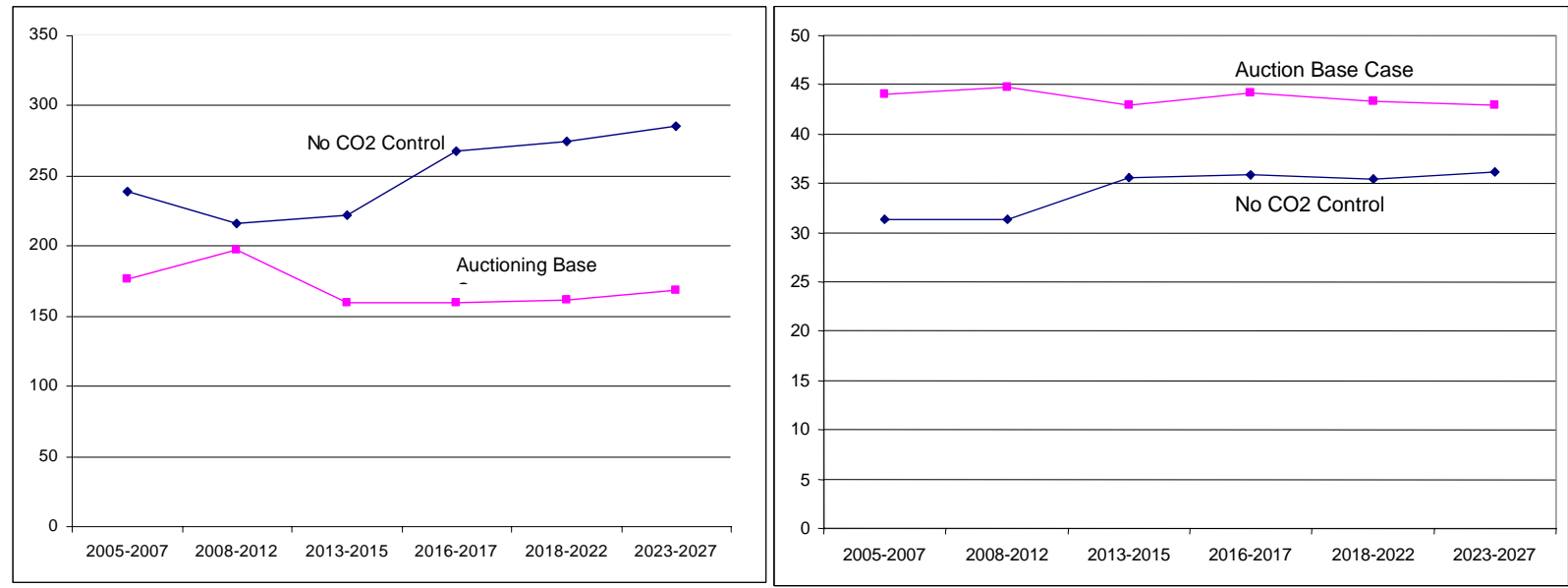

Figure $3 \mathrm{CO}_{2}$ Emissions and Baseload Price with Auctioning Base Case (GB only)

Note: $\mathrm{CO} 2$ prices fixed at $20 € / \mathrm{tCO} 2$.

\subsubsection{Updating with an out-put based uniform benchmark}

To update allocation, governments may consider using benchmarks. How does the choice of benchmark impact electricity prices and $\mathrm{CO}_{2}$ emissions? We start by quantifying impacts of the simplest form of updating: using an output-based uniform benchmark (OB, UB). In this case, the allocation in the following compliance period is equal to the product of the benchmark and electricity production in the preceding compliance period (Palmer and Burtraw 2004). To avoid distortions between any sources of power generation the uniform benchmark also envisages the allocation of $\mathrm{CO}_{2}$ allowances to low carbon technologies like wind, hydro, solar or nuclear. 
The simulation results for GB presented in this section assume that all power stations receive for free, an allowance of $0.35 \mathrm{tCO}_{2}$ per MWh electricity produced in the preceding compliance period. This benchmark is phased out linearly so that by 2023 no further allocation is received. In the model it is also assumed that GB is small relative to the European market such that even with changing GB emissions the $\mathrm{CO}_{2}$ price stays at $€ 20 / \mathrm{t} \mathrm{CO}_{2}$. The simulation results in Figure 4 show that the electricity price increases but by far less than in the auction case.

(a) CO2 Emissions (MMTonnes)

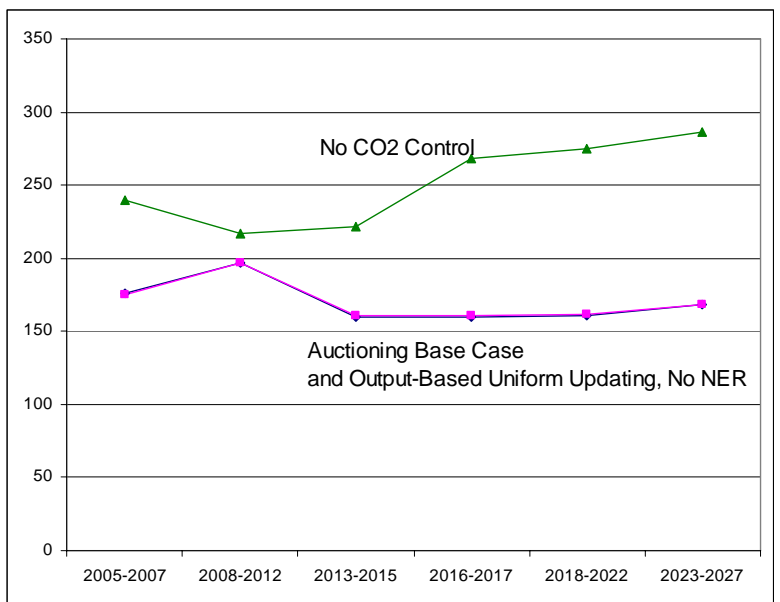

(b) Baseload Electricity Price (Euro 2005/MWh)

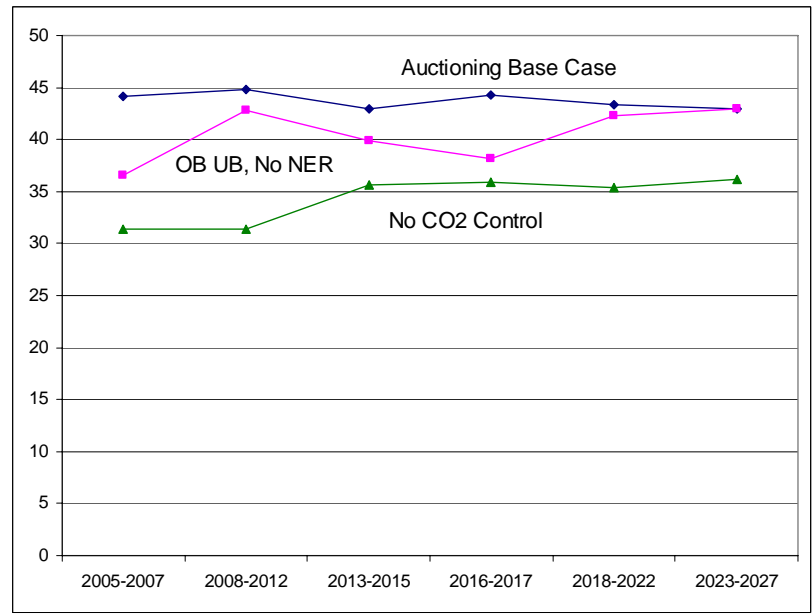

Figure $4 \mathrm{CO}_{2}$ Emissions and Baseload Price with Updating Using an Output-Based Uniform Benchmark (GB only, €20/tCO2)

Figure 4 also shows the impact on $\mathrm{CO}_{2}$ emissions was very small when compared to the auction case. While lowering electricity prices, updating using an output-based uniform benchmark does not result in any significant increase in $\mathrm{CO} 2$ emissions. The benefits of future allocation reduced the production costs of operation resulting in a reduction in prices without affecting the dispatch order. Output-based updating therefore acts as a production subsidy (Fisher 2001).

This, however, may not be the whole story. For modelling purposes we assumed that demand was exogenous. In reality electricity demand is price elastic, especially in the mid and long term, when higher prices induce more energy efficient investment. Hence we expect electricity demand to increase with the output based updating. To meet this additional demand, more generation is required resulting in an increase in $\mathrm{CO}_{2}$ emissions. 
For modelling purposes we also assumed a fixed $\mathrm{CO}_{2}$ price did not constrain $\mathrm{CO}_{2}$ emissions. However, if updating increases $\mathrm{CO}_{2}$ emissions on a European scale, then allowance prices will appreciate, and this in turn will compensate for (some) of the previous electricity price reductions.

\subsubsection{Updating with a fuel-specific benchmark}

As basing Phase II allocation on activities in Phase I is explicitly prohibited by the EU Directive, some MSs update allocations using fuel-specific benchmarks (FSB) where the benchmark is set higher for coal-fired plants than for gas-fired plants. Here, we assess the impact of this alternative updating method and compare with the output-based uniform benchmark approach.

In our model gas-fired plants receive $0.35 \mathrm{tCO}_{2}$ and the coal-fired power stations receive $0.75 \mathrm{t}$ $\mathrm{CO}_{2}$ per MWh generated in the preceding compliance period. ${ }^{6}$ The results for our GB simulation are shown in Figure 5. The fuel-specific updating scenario leads to higher $\mathrm{CO}_{2}$ emissions and electricity price are lower because of the output subsidy but $\mathrm{CO}_{2}$ emissions are significantly above the auctioning case.
(a) CO2 Emissions (MMTonnes)
(b) Baseload Electricity Price (€ 2005/MWh)

\footnotetext{
${ }^{6}$ Although technology-specific benchmarks may be intended as incentives for clean technologies, at the same time, it also provides channels to make "concessions" for technologies and sites that cannot achieve lower emission targets (Entec and NERA, 2005)
} 

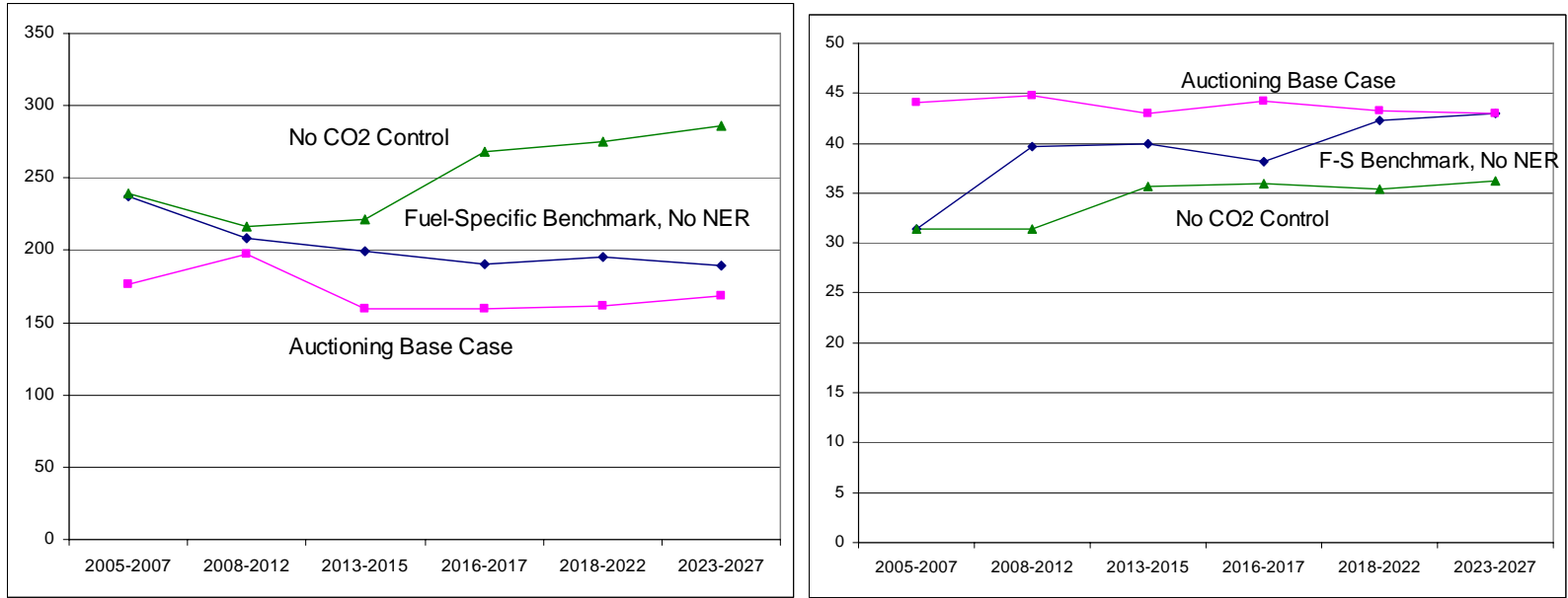

Figure $5 \mathrm{CO}_{2}$ Emissions and Baseload Price with Updating Using an Fuel-Specific Benchmark (GB only, 20€/tCO2)

\subsubsection{Updating in an International context}

To test the net impact that updating can have on the efficiency of the EU ETS as a whole, we simulate four scenarios for all countries in Europe. The IPM treats the electricity dispatch system as a system of integrated and interconnected markets. It assumes that the competitive market allows for the optimal operation decisions of power stations across multiple jurisdictions. The first scenario defines the business-as-usual case ("No $\mathrm{CO}_{2}$ control”), and the second simulates a situation where all European countries use allocation by auctioning and a price of $€ 20 / \mathrm{t} \mathrm{CO}_{2}$. For the final two cases, we apply different allocation methodologies to the UK, Germany and the Netherlands: first an output-based uniform benchmark, and then a fuel-specific benchmark. All other European countries continue to auction allowances. The impact of updating in these three countries on $\mathrm{CO}_{2}$ emissions is reported for 2008-2012 in Figure 6 below. 


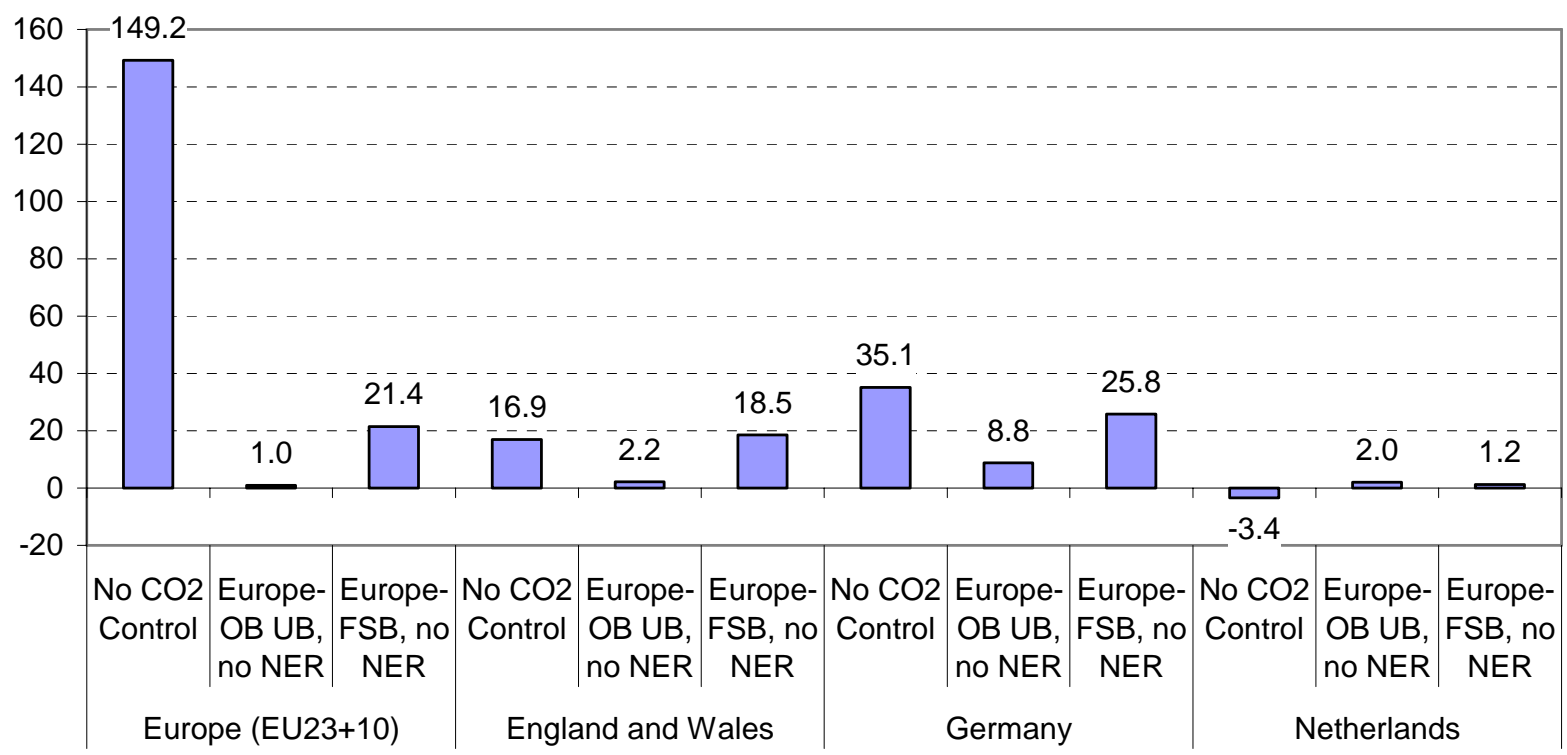

Figure $6 \mathrm{CO}_{2}$ Emissions with Base Case, Updating Using Output-Based Uniform Benchmark and FuelSpecific Benchmark for Europe (EU23+10), England and Wales, Germany and The Netherlands (20€/tCO2, 2008-2012 only)

On an overall European scale, the results show that updating using an output-based uniform benchmark in the UK, Germany and the Netherlands has a smaller impact on emissions than using a fuel-specific benchmark in the same three countries. The no $\mathrm{CO}_{2}$ control case results in the highest emissions. Emissions were lowest with all countries adopting the auctioning approach.

Comparing the impact of different allocation procedures for the three individual countries we observe a similar behaviour in Germany and England \& Wales. Distortions in the allocation process mean that $\mathrm{CO}_{2}$ emissions increase from the auction to the output based uniform benchmark case and then again to the output based fuel specific benchmark case. Emissions are highest in the no $\mathrm{CO}_{2}$ control case. The Netherlands proved a special case with emissions in the BAU case lying below the auction case. Two explanations underlie these results: First, the large share of gas-fired plants makes the Netherlands a preferred country for electricity generation 
under emission trading. Second, the high level of interconnection with neighbouring countries allows trade to utilise this opportunity.

These numerical simulations provide useful insight into the magnitude of distortions induced by allocation to the power sector. Since the $\mathrm{CO}_{2}$ emissions cap for Europe is fixed, high $\mathrm{CO}_{2}$ emissions projections imply increased scarcity and allowance prices. This could induce increased flow of allowances through the flexible mechanisms of the Kyoto Protocol, including Clean Development Mechanism (CDM) and Joint Implementation (JI). The extent to which $\mathrm{CO}_{2}$ prices would have to adjust to achieve the same level of European-wide emissions is a question in need of further research.

\subsection{Closure Rules: the impact of 'contingent allocation'}

With a permanent allocation, the ownership of the allowances remains unaffected by closure of the power station. If the continued operation of a plant is no longer profitable, then owners can sell the allowances and close the plant.

Closure decisions are distorted if allocation of allowance is contingent on activity level of a plant. Plant owners retain plants on the system and continue operation at minimum run conditions in order to receive allowances in the next trading period ${ }^{7}$

In addition, most countries, with the exception of Sweden and the Netherlands, explicitly include closure rules within their NAPs. For example in Germany, entities that close down operations (defined as emitting less than $10 \%$ of its average annual baseline emissions) will not receive allowances from the following year. Such formal closure rules further discourage the closure of

${ }^{7}$ To address such distortions, Ahman et al (2006) propose a “The Ten Year Rule” which they argue can parallel incentives of permanent grandfathering hence eliminate the trade-off between updating and permanent allocation. 
inefficient plants within a trading period, as allocation essentially becomes a subsidy for continued production (Ãhman et al. 2006).

These closure rules have consequences for the power system. First, with more plants staying on the system, there is more electricity supply and therefore prices can initially be reduced. Secondly, as inefficient old plants are artificially retained on the system, investment in more efficient new plants is delayed. This increases power prices and $\mathrm{CO}_{2}$ emissions.

We quantify the impact of the implicit closure rules for the Great Britain electricity system: If a power plant closes it does not receive any allocation in the following compliance period. Table 1 lists the initial annual allocation of allowances to the different technologies. We assume that this is the allowance allocation for the period 2005-2008 and will be linearly phased out until 2028. We again fix the $\mathrm{CO}_{2}$ price at $€ 20 / \mathrm{tCO}_{2}$.

\begin{tabular}{|r|r|}
\hline & $\begin{array}{r}\text { Initial allocation } \\
\text { (tCO2/MWyr) }\end{array}$ \\
\hline CCGT (combined cycle gas turbine) & 1,893 \\
\hline OCGT (open cycle gas turbine) & 473 \\
\hline Hydro (pumped storage or pondage hydro); & 0 \\
\hline Diesel generator & 947 \\
\hline Nuclear & 0 \\
\hline Conventional coal boiler & 0,840 \\
\hline Conventional steam turbine (burning fossil fuel other than coal) & 1,420 \\
\hline
\end{tabular}

Table 1 Assumed Initial Allocation to Incumbents for Period 2005-2007 
Comparing results for the cases where allocation of allowances is contingent on plant existence during the 3-5 year allocation period with the base case (auction or permanent grandfathering) the number of retirements of plants falls. With no $\mathrm{CO}_{2}$ constraint only $0.4 \mathrm{GW}$ of capacity was retired for economic reasons. In the auction case, 7.1 GW of capacity is retired by 2015 and 14.2GW by 2022. In contrast, free allocation to existing plants reduces cumulative retirements to 2.5GW and 7.2GW over the same periods. This reduces the investment in new lower carbon plant. For our parameter choice we did not observe strong effects of contingent allocation on $\mathrm{CO}_{2}$ emissions. Power prices are slightly lower in the contingent allocation case. As the later scenario analysis for new entrant allocation illustrates, such results can drastically change with small changes to the parameter choices.

\subsection{Summary of allocation to existing facilities}

The allocation procedures applied by National Allocation Plans combine various aspects discussed in this section. Figure 7 illustrates and summarises the transition from an efficient allocation based on auction (or permanent grand fathering) to the various dimensions of distortions that are created by the iterative grandfathering approach using a moving baseline in current national allocation plans.

\begin{tabular}{|c|c|c|c|c|c|c|c|}
\hline & \multicolumn{6}{|c|}{ Allocation Method } \\
\hline & & \multirow{2}{*}{ 莺 } & \multirow{2}{*}{ 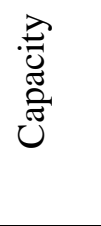 } & \multirow{2}{*}{ 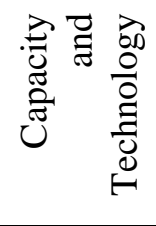 } & \multirow{2}{*}{ 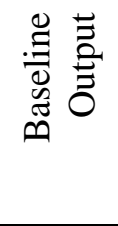 } & \multirow{2}{*}{ 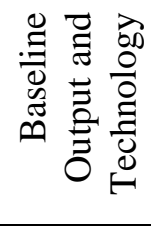 } & \multirow{2}{*}{ 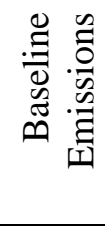 } \\
\hline Impacts & Distortions & & & & & & \\
\hline \multirow{2}{*}{$\begin{array}{c}\text { Excess CO2 } \\
\text { Intensive Capacity }\end{array}$} & $\begin{array}{r}\text { Discourage Plant } \\
\text { Closure }\end{array}$ & & $X$ & $X$ & $X$ & $\mathrm{X}$ & $X$ \\
\hline & $\begin{array}{r}\text { Discourage Closure } \\
\text { of Inefficient Plant }\end{array}$ & & & $\mathrm{X}$ & $\mathrm{X}$ & $\mathrm{X}$ & $\mathrm{X}$ \\
\hline $\begin{array}{l}\text { Inefficient Fuel } \\
\text { Choice }\end{array}$ & $\begin{array}{l}\text { Increase Operation } \\
\text { of Inefficient Plant }\end{array}$ & & & & $\mathrm{X}$ & $X$ & $X$ \\
\hline $\begin{array}{l}\text { Less Energy } \\
\text { Efficiency } \\
\text { Investments }\end{array}$ & $\begin{array}{r}\text { Reduce Incentives } \\
\text { for Energy } \\
\text { Efficiency } \\
\text { Investments } \\
\end{array}$ & & & & & & $\mathrm{X}$ \\
\hline
\end{tabular}

Figure 7 Effect of Allocation Methods to Power Sector Incumbents 
The economically efficient allocation methods are auctions or a one-off free allocation of allowances. The first set of distortions is introduced if allowances are only allocated in the future, if the power stations are operational today. The value of future allocations delays closure of plants beyond the socially efficient lifespan. This effect is reinforced if the amount of allocation is increasing with the $\mathrm{CO}_{2}$ intensity of the technology. With such technology specific allocation more $\mathrm{CO}_{2}$ intensive technologies receive additional encouragement to stay operational, further delaying the shift towards less $\mathrm{CO}_{2}$ intensive power stations.

The second set of distortions follows, if the amount of future allocations is related to current electricity production. A uniform benchmark would not create distortions between the operation of different technologies. In our model the uniform updating resulted in lower electricity prices. We did not look at the impact on electricity demand and implied changes of CO2 emissions. Output based updating also implements a closure condition - only power stations that produce will receive allowances in the future. Thus it creates some distortions discussed above. Many of the discussions about output-based benchmarks assumed that these benchmarks are fuel or technology specific. Updating based on such benchmarks does create strong distortions in the operation and can create significant increases of $\mathrm{CO}_{2}$ emissions.

Reality can offer even more distortions. The allocation of $\mathrm{CO}_{2}$ allowances in Phase I of the EU ETS was based on base line CO2 emissions and the current discussions surrounding Phase II indicate that this will remain the dominant metric. Among our model runs the fuel specific benchmark using a moving base line best reflects the distortions created by the emission based NAPs assuming they also use a moving base line. The emission based updating creates additional distortions not captured by our model run. First, it reduces the incentive to operate the 
more efficient power stations of the same fuel type. This may not be a large problem as generators typically prefer to run more fuel efficient power stations. Second, the emission-based allocation reduces the incentives to invest in efficiency improvements of existing and new power stations.

As the European budget for $\mathrm{CO}_{2}$ emissions is capped, if many Member States implement this allocation methodology, increases of national emissions are likely to push up the European price of $\mathrm{CO}_{2}$ allowances. They in turn increase the electricity prices across all states, thus the subsidyeffect of free allocation that lowers electricity prices is partly offset.

\section{Allocation to New Entrants}

We assess the economic incentives and their impacts resulting from allocation to new projects of power generators. All MS have made provisions that guarantee a certain volume of free allowances to new entrants for a defined period. Section 3.1 uses a simple analytic model to illustrate the impact of a uniform allocation of $\mathrm{CO}_{2}$ allowances to all new projects, section 3.2 discusses how increased allocation to coal affect the equilibrium. In section 3.3 we then use a numerical model to calculate the impacts of different allocation schemes in the UK and European system, taking into consideration the existing assets and investment pathways. Finally section 3.4 summarises the results of all model runs.

NE provisions are often viewed as a "general" or "synthetic" compensation mechanism in the EU ETS. For example, by encouraging firms to establish new sources rather than to expand operation of existing facilities, it aims in part to compensate for distortions created by closure conditions including delaying the shift towards new efficient investment. Also it sometimes 
argued that NE provisions create 'fairness' among incumbents and new entities; if existing facilities receive allowances, so should new facilities. Barriers to entry for new firms due to inadequate liquidity in the market may be a more appropriate but also difficult justification for NE allocations (Baron and Bygrave 2002). Free NE allocations compensate for the direct additional costs incurred by new entrants to the market. By improving their access to capital, free allowances can facilitate entry by new firms, hence NE reserves address wider issues of market power (Ãhman et al. 2006) and thus increase competition within rather concentrated national European electricity markets (Ãhman and Zetterberg 2003); Pedersen (2002) in (Baron and Bygrave, 2002). As most new projects are initiated by existing utilities, the expression new entrant allocation seems a bit misleading and could perhaps be replaced by new project allocation in future discussions.

Most Phase I NAPs provide for NE allocations based on a general emission rate and forecasted activity level. For example in the Netherlands (NL), new entrants are allocated allowances based on projected output or fixed cap factor multiplied with uniform emission rate in line with that of a CCGT. In France Germany and Poland, CO2 intensive power generators like coal-fired installations receive the highest number of allowances per $\mathrm{kW}$ installed. The literature highlights the danger that NE provisions can create distortions (Harrison and Radov 2002). In order to illustrate how these rules can impact electricity prices, and $\mathrm{CO}_{2}$ emissions on our GB simulations, we focus on two approaches: one based on a uniform benchmark and one based on fuel-specific benchmark. In both cases the forecasted capacity factor of new entrants is fixed at $60 \%$.

\section{1 New entrant allocation with a uniform benchmark}

To illustrate the impact of new entrant allocation we calculate the long-term investment equilibrium for a competitive electricity market. Section 3.3 will subsequently assess the impact 
in real electricity markets where existing generation assets do effect the generation and price structure.

In our simplified model we assume that the highest prices are set by demand side response, followed a combined cycle gas turbines with high variable and low fixed costs and coal power stations with low variable and high fixed costs. We compare two cases. First, the system is small relative to the $\mathrm{EU}$ emission-trading scheme and the $\mathrm{EU} \mathrm{CO}_{2}$ price is not affected by changes in national emissions of $\mathrm{CO}_{2}$. Second, the model represents the entire EU ETS, and we set a fixed $\mathrm{CO}_{2}$ budget and endogenously determined $\mathrm{CO}_{2}$ price.

The results with uniform NE allocation are shown in Figure 8. With a fixed allowance price, as the value of the NE allocations increases, additional gas power stations replace peaking generation, usually provided by open cycle gas turbines, or demand response as the value of the allocation increases. The electricity price falls and $\mathrm{CO}_{2}$ emissions fall. Nevertheless, at a certain value of total NE allowances (between $€ 40$ and $€ 50 / \mathrm{Kw} / \mathrm{hr}$ ), the option for CCGT to replace peakers is exhausted and it becomes viable to invest in a new coal-powered stations. From this point onwards, coal-fired power stations are built in preference to CCGT. This results in significant increases in $\mathrm{CO}_{2}$ emissions even as electricity prices continue to fall. 


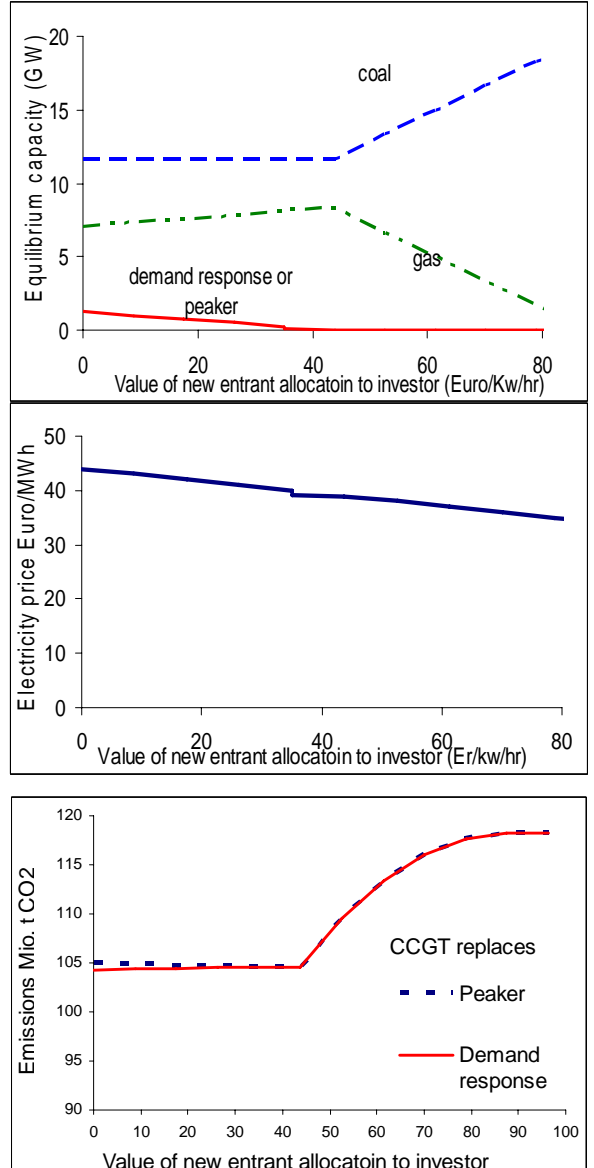

(a)

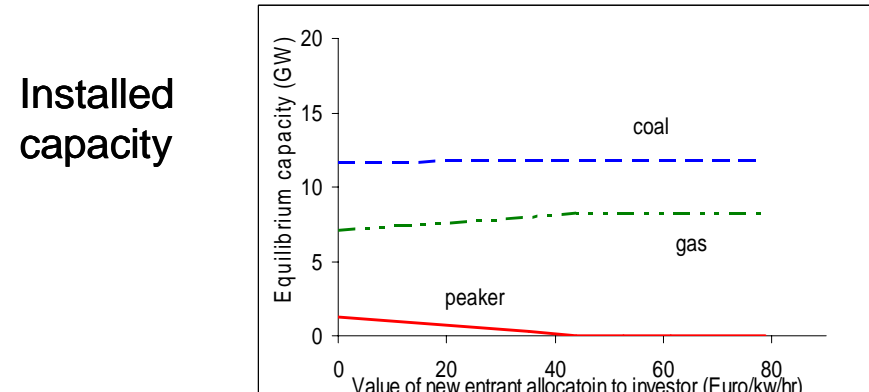

Price

$\mathrm{CO} 2$

Emissions

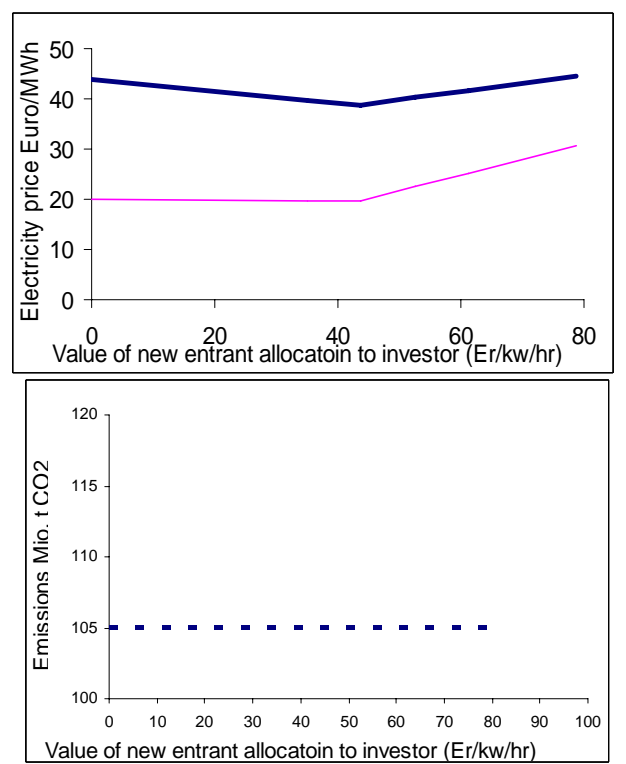

(b)

Figure 8 Long-term equilibrium effect of increasing levels of uniform new entrant allocation

The right hand side of Figure 8 shows what happens if same uniform new entrant allocation provision is applied at the European level, i.e. when the $\mathrm{CO}_{2}$ budget is fixed. When the value of the new entrant allocation is sufficiently high that construction of new coal powered stations is made viable, with a fixed $\mathrm{CO}_{2}$ cap, however, the equilibrium price of $\mathrm{CO}_{2}$ will increase and the higher exposure of coal power stations to $\mathrm{CO}_{2}$ prices reduces the expected benefit of operating the coal power station. This prevents the additional construction of coal-powered stations. Higher $\mathrm{CO}_{2}$ prices, however, feed through to higher electricity prices. 


\section{2 New entrant allocation with a fuel-specific benchmark}

Figure 9 illustrates the effect of a fuel-specific new entrant allocation in the long-run equilibrium.

With a fixed $\mathrm{CO}_{2}$ price, the additional support for coal-powered stations implies that even small values of new entrant allocation result in incentives to replace gas with coal powered stations.

Over a mid to long-term time horizon, this increases national $\mathrm{CO}_{2}$ emissions and lowers electricity prices. With a fixed $\mathrm{CO}_{2}$ budget, the cap on total emissions implies that $\mathrm{CO}_{2}$ prices must rise. The higher $\mathrm{CO}_{2}$ prices again feed through to higher electricity prices.
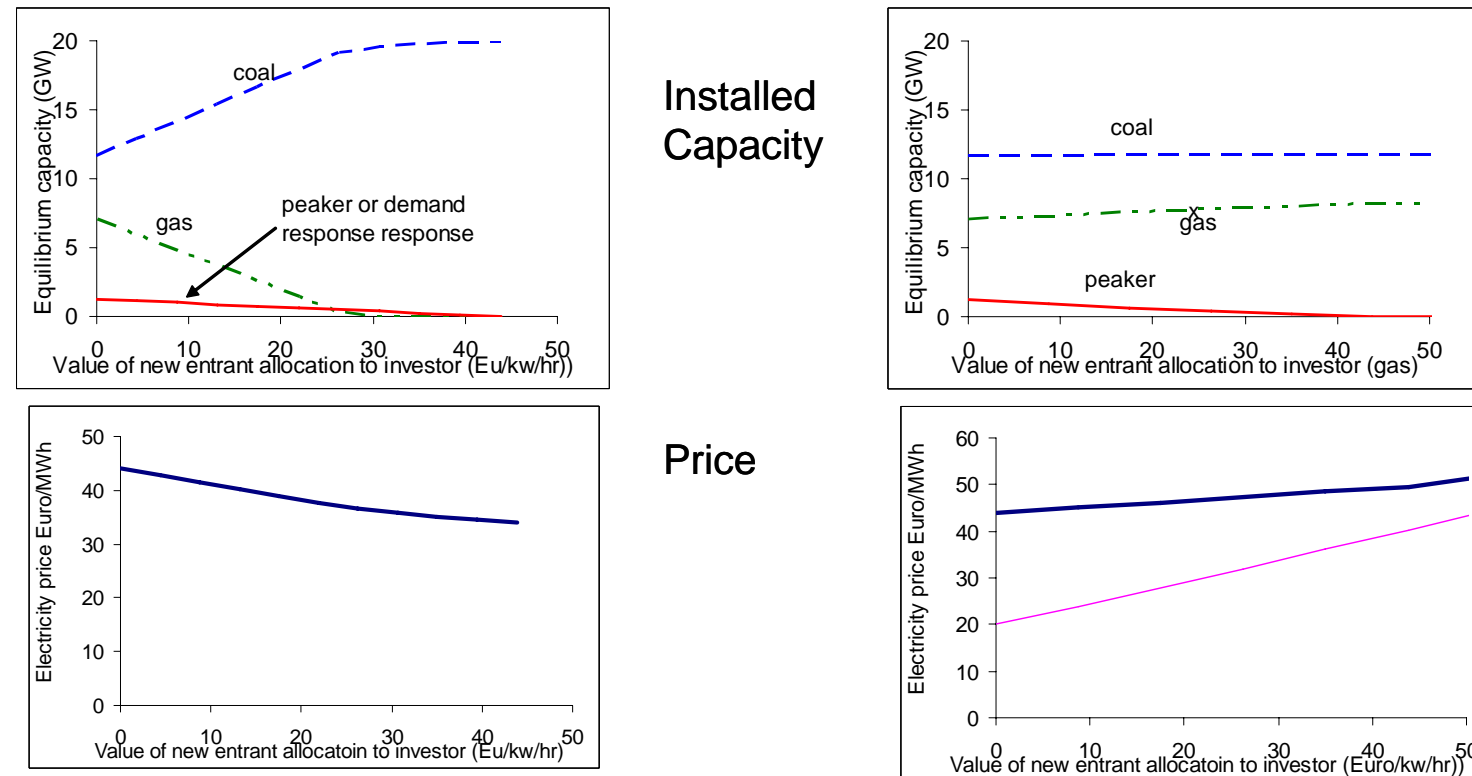

Price

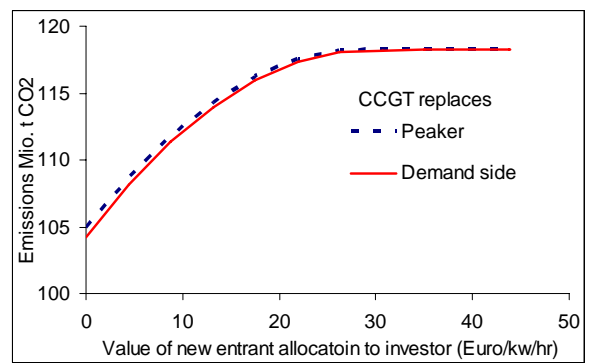

$\mathrm{CO} 2$

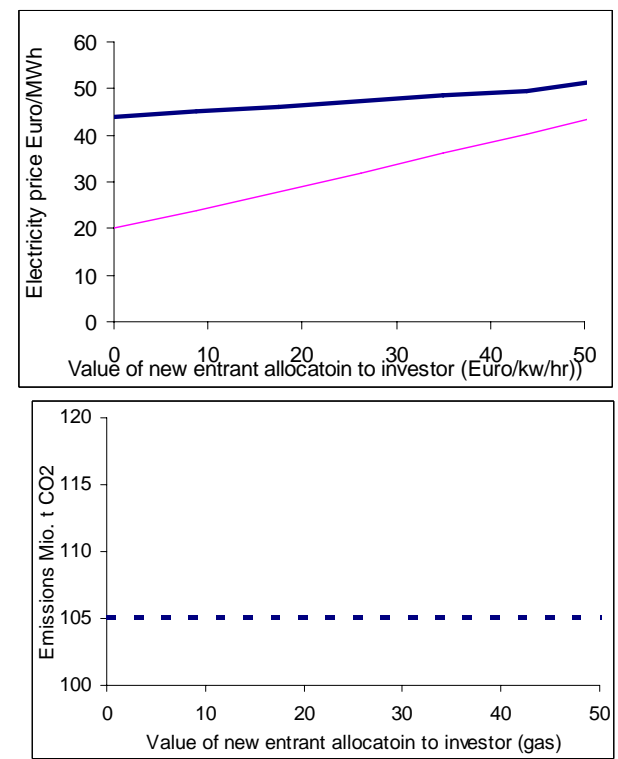

(a)

(b)

Figure 9 Long-term equilibrium effect of increasing levels of fuel-specific new entrant allocation

This analysis highlights the dangers of a fuel-specific new entrant allocation at the European level. In equilibrium, fuel-specific benchmarking increases the social costs of complying with the $\mathrm{CO}_{2}$ cap. 


\subsection{Aggregate impact on $\mathrm{CO}_{2}$ emission and electricity prices for Europe}

We also used the IPM to assess how updating and new entrant allocation can affect the evolution of the power system in England and Wales for a series of cases with a fixed $\mathrm{CO}_{2}$ price. For 20052007, NE allocation based on a uniform benchmark assumes a benchmark rate of $0.35 \mathrm{t}_{2}$ per MWh for all power plants together with an annual load factor of $60 \%$ for both technologies. The fuel-specific NE allocation assumes $0.75 \mathrm{t} \mathrm{CO}_{2}$ per $\mathrm{MWh}$ for new coal-fired plants. The allocation drops linearly over time so that by $2028 \mathrm{NE}$ would have to purchase all their allowances from the market. Figure 10 summarises the results, which are taken from our European simulation. In these Germany, the Netherlands and the UK were all subject to the alternative allocation method whilst all other countries applied auctioning or perfect grandfathering.

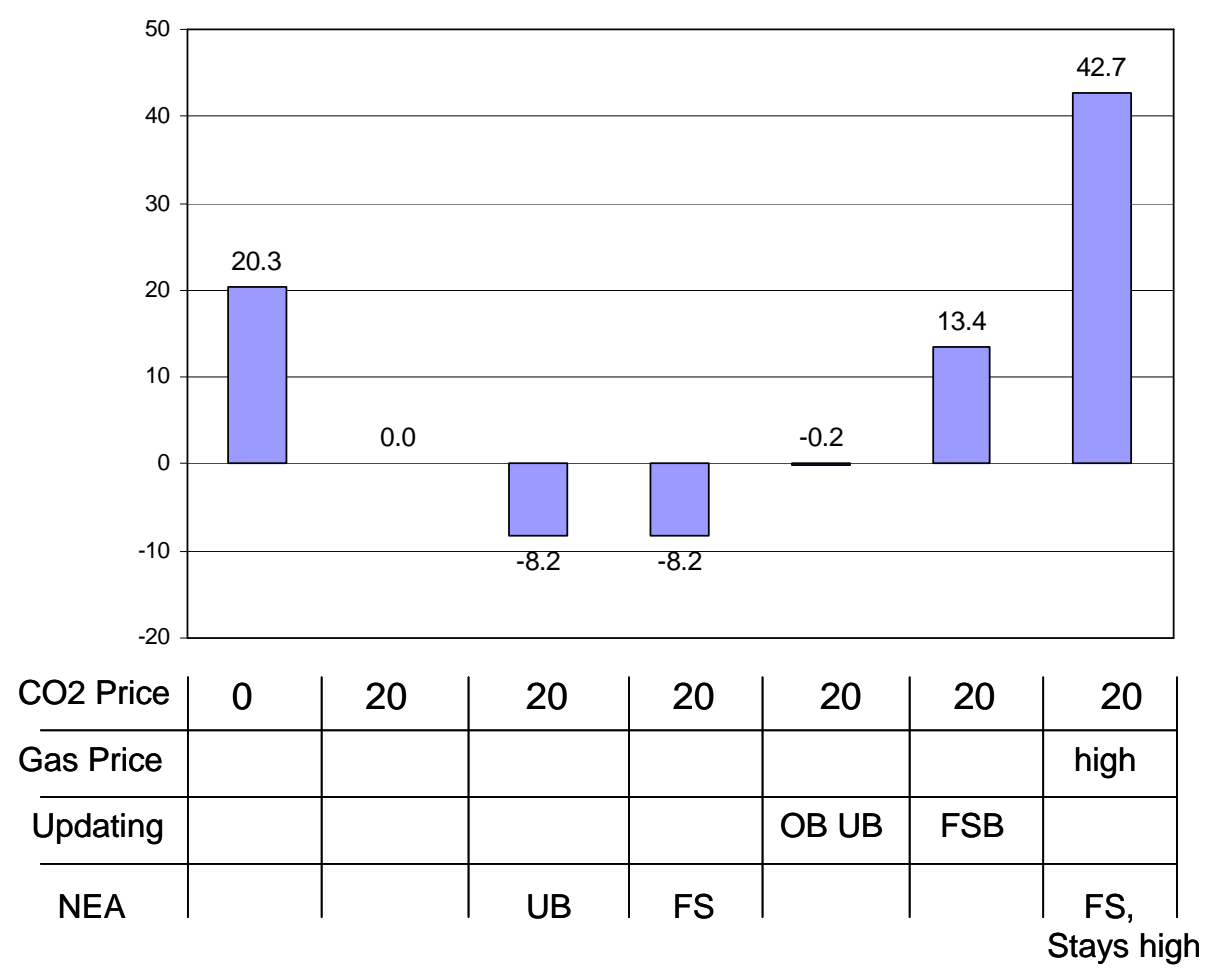

Figure 10 Effect of various allocation methods on England \& Wales CO2 emissions in period 2008-2012 (assuming fixed $\mathrm{CO} 2$ price)

Starting with a base case assuming no updating or $\mathrm{NE}$ allocation, $\mathrm{CO}_{2}$ emissions decrease when 
a NE allocation is used. The allocation results in accelerated construction and operation of combined cycle gas turbines and thus lower $\mathrm{CO}_{2}$ emissions. For our given set of input parameters, the results for uniform-benchmark or fuel-specific benchmark were the same. The subsidy to coal was not large enough to justify any construction of new coal. The resulting reduction in $\mathrm{CO}_{2}$ emissions, however, could be dramatically reversed. When we increased the price of natural gas above $4.9 € / \mathrm{MMBTu}$ and assumed that there would be no fall in the allocation over time, coal became the preferred new build option. Emissions of $\mathrm{CO}_{2}$ would increase above the No $\mathrm{CO}_{2}$ and fuel-specific updating cases. The implementation of uniform updating did not effect emissions. If however updating is fuel specific, e.g. producers with coal power stations expect higher future allocations than producers with gas, then dispatch decisions are distorted and emissions increase.

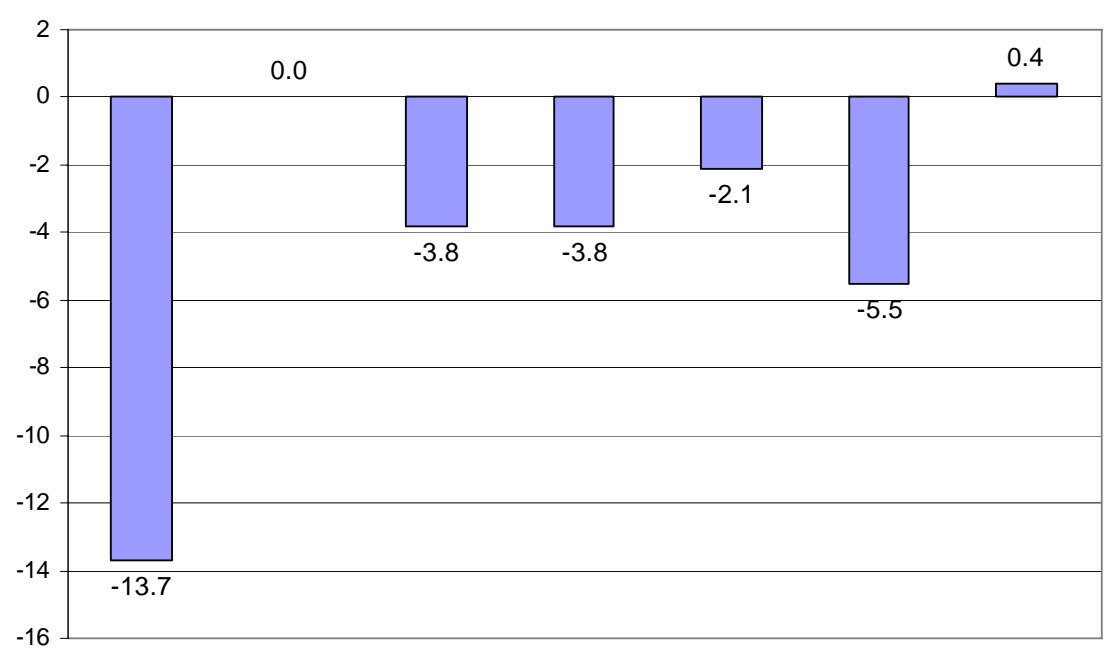

\begin{tabular}{c|c|c|c|c|c|c|c|} 
CO2 Price & 0 & 20 & 20 & 20 & 20 & 20 & 20 \\
\hline Gas Price & & & & & & & high \\
\hline Updating & & & & & OB UB & FSB & \\
\hline NEA & & & UB & FS & & & $\begin{array}{c}\text { FS, } \\
\text { Stays high }\end{array}$
\end{tabular}

Figure 11 Effect of various allocation methods on England \& Wales prices in period 2008-2012 (assuming fixed CO2 price) 
Figure 11 illustrates the impact on electricity prices of the different allocation methods for the same England \& Wales cases. The simulations are run on the assumption that European $\mathrm{CO}_{2}$ prices are not affected by the changes of $\mathrm{CO}_{2}$ emissions in the UK. If various EU countries implement allocation plans that would increase national $\mathrm{CO}_{2}$ emissions, then this assumption is no longer valid, and $\mathrm{CO}_{2}$ prices will rise and feed through to higher electricity prices.

\subsection{Summary of the numerical results}

Figure 12 summarises the impact of different allocation methods examined for our GB simulation which are based on the assumption that the UK emission pattern will have limited impact on the European allowance price which is therefore set as fixed. 


\begin{tabular}{|c|c|c|c|c|c|}
\hline & $\begin{array}{l}\text { Average } \mathrm{CO} 2 \\
\text { emissions } \\
\text { (million tCO2) }\end{array}$ & $\begin{array}{c}\text { Average } \\
\text { baseload prices } \\
(€ / \mathrm{MWh})\end{array}$ & $\begin{array}{l}\text { Cumulative } \\
\text { retirements } \\
\text { (MW) }\end{array}$ & $\begin{array}{l}\text { Average Gas } \\
\text { use (TBTU) }\end{array}$ & $\begin{array}{c}\text { Average Coal } \\
\text { use (TBTU) }\end{array}$ \\
\hline $\begin{array}{l}\text { No Closure test, } \\
\text { High FS NER, } \\
\text { High Gas price }\end{array}$ & 241 & 45.26 & 12,977 & 359 & 1,623 \\
\hline No CO2 & 226 & 32.79 & 556 & 1,221 & 1,628 \\
\hline $\begin{array}{c}\text { FS Upd, No } \\
\text { NER }\end{array}$ & 215 & 37.01 & 5,118 & 1,325 & 1,440 \\
\hline $\begin{array}{c}\text { Closure test, No } \\
\text { NER }\end{array}$ & 187 & 43.28 & 3,318 & 1,694 & 946 \\
\hline $\begin{array}{c}\text { Closure test, Uni } \\
\text { NER }\end{array}$ & 180 & 41.86 & 3,678 & 1,766 & 829 \\
\hline $\begin{array}{c}\text { Closure test, FS } \\
\text { NER }\end{array}$ & 180 & 41.86 & 3,678 & 1,766 & 829 \\
\hline $\begin{array}{c}\text { Uni Upd, No } \\
\text { NER }\end{array}$ & 178 & 39.72 & 10,640 & 1,804 & 776 \\
\hline $\begin{array}{c}\text { Auctioning Base } \\
\text { Case }\end{array}$ & 178 & 43.96 & 10,629 & 1,798 & 780 \\
\hline $\begin{array}{c}\text { No Closure test, } \\
\text { Uni NER }\end{array}$ & 170 & 41.81 & 20,597 & 1,863 & 670 \\
\hline $\begin{array}{c}\text { No Closure test, } \\
\text { FS NER }\end{array}$ & 170 & 41.81 & 20,597 & 1,863 & 670 \\
\hline
\end{tabular}

Figure 12 Impact from allocations for period 2005-2017 (GB simulation only)

Uniform allocation of allowances creates the fewest distortions for both incumbents and new entrants. For a fixed $\mathrm{CO}_{2}$ price the uniform benchmarks for allocation to existing and new facilities resulted in a reduction of electricity prices with limited impact on $\mathrm{CO}_{2}$ emissions. We caution that this 'optimistic' result is based on price independent electricity demand and our assumptions on available technologies and fuel prices. Furthermore, the reduction of electricity prices is typically far lower than the value of the free allowances, as investors and operators 
discount $\mathrm{CO}_{2}$ price and regulatory uncertainty. Thus uniform allocation of allowances can be interpreted as an inefficient capacity payment scheme.

Fuel-specific benchmarks applied to existing power stations create incentives to shift production towards more $\mathrm{CO}_{2}$ intensive generators. Whether we refer to fuel-specific updating or NE allocation, for any given price of $\mathrm{CO}_{2}$, these allocation methods will result in $\mathrm{CO}_{2}$ emissions in excess of the auctioning case. If operators and investors expect that future national allocation plans are similar to current national allocation plans, then they anticipate receiving fuel specific allocation in the future. If the $\mathrm{CO}_{2}$ budget were fixed, this would imply that $\mathrm{CO}_{2}$ prices, and hence electricity prices, would have to rise.

\section{Conclusions}

This paper illustrates the set of distortions that can result from allocation of $\mathrm{CO}_{2}$ allowances to existing facilities and new entrants in the form of closure rules where allocation is lost once the facility shuts down, updating where allocation in forthcoming compliance periods is a function of generation or emissions levels today, and allocations to new entrants based on alternative benchmarks..

We illustrated the set of distortions that can result from allocation of $\mathrm{CO}_{2}$ allowances to existing facilities and new entrants.

The first set of distortions is introduced with uniform updating (e.g. based on past power output). From a national perspective, assuming fixed $\mathrm{CO}_{2}$ prices, free allowances reduce the opportunity costs (updating) or scarcity prices (new entrant allocation) and thus feed through to somewhat lower electricity prices. The regulatory uncertainty involved in the future benefit might imply 
that the decrease in electricity prices might be far lower than the value of allowances handed out.

The failure to internalise the $\mathrm{CO}_{2}$ externality into the electricity prices limits investment in energy efficiency and results in higher electricity consumption. Thus electricity production and national $\mathrm{CO}_{2}$ emissions increase. If all European countries implement such policies the suggested higher $\mathrm{CO}_{2}$ emissions would translate into higher $\mathrm{CO}_{2}$ prices and feed through to higher electricity prices.

Overall, a purely uniform allocation of allowances creates the fewest distortions for both incumbents and new entrants. A similar approach for both facilities would increase transparency and avoid difficulties of defining what a new entrant is relative to an existing facility (Entec and NERA 2005). However, this does not suggest that it is desirable from an equity perspective, as power generators might receive free allowances above the level they require to cover any additional costs from the emission-trading scheme.

A justification for the free allocation of allowances is that they are used to compensate emitters for otherwise reduced profitability due to the introduction of ETS. This would argue for fuel and technology specific allocation. Relative to the distortions created by uniform benchmarking this has the following impacts. Fuel specific benchmarks applied to existing power stations create incentives to shift production towards more $\mathrm{CO}_{2}$ intensive generators. This can increase $\mathrm{CO}_{2}$ emissions, and if applied on a European scale it can increase $\mathrm{CO}_{2}$ prices. These feed through to higher electricity prices.

Fuel specific allocation to new entrants creates additional incentives to invest in $\mathrm{CO}_{2}$ intensive power stations. The long-term equilibrium model illustrated, that if investors are forward looking they anticipate that any additional construction of coal power stations would result in additional 
operation of the power station. The fixed $\mathrm{EU}$ allowance budget prevents additional $\mathrm{CO}_{2}$ emissions and would thus push up $\mathrm{CO}_{2}$ prices to a level at which investment in $\mathrm{CO}_{2}$ intensive power stations is unprofitable. Thus fuel specific new entrant allocation increases $\mathrm{CO}_{2}$ and electricity prices.

Allocation relative to past emissions is prevalent in current national allocation plans. If such direct updating is to continue, then the incentives ETS could have on existing power stations to increase fuel and $\mathrm{CO}_{2}$ efficiency are severely reduced. Any improvement will reduce the future allowance allocation. The announcement of the Commission from May 2006 to use 2005 emission data in the evaluation of national allocation plans for the period 2008-2012 illustrates that policy makers cannot credibly commit to ignoring available information in the allocation process. ${ }^{8}$

We note that national allocation plans were designed in anticipation of some of these distortions. The national allocation plans aimed to counter some of these distortions, e.g. by transfer provisions between power stations. However, it seems impossible to comprehensively address the complex set of interactions of incentives from various provisions in NAPs. Any such assessment tends to be valid for only one scenario.

Nevertheless, despite the complex interactions, we have shown that it is possible with the aid of simulation tools to make an assessment of the distortionary impact of allocation procedures both at the national and international level. These approaches provide a useful tool to policy makers as they try to seek to design new provisions for forthcoming NAPs. Our numerical calculation for the UK assuming a fixed $\mathrm{CO}_{2}$ price illustrated how quantitative results can invert with a

\footnotetext{
${ }^{8}$ Source: Pointcarbon, 15.5.2006
} 


\section{Reference}

Ãhman, M., D. Burtraw, J. A. Kruger and L. Zetterberg (2006) The Ten-Year Rule: Allocation of Emission Allowances in the EU Emissions Trading System. Energy Policy Forthcoming.

Ãhman, M. and L. Zetterberg (2003) Options for Emissions Allowance Allocation under the EU Emissions Trading Directive. IVL Discussion Paper.

Baron, R. and S. Bygrave (2002) Towards International Emissions Trading: Design Implications for Linkages. OECD/IEA Information Paper.

Bernard, A. L., C. Fischer and M. Vielle (2001) Is There a Rationale for Rebating Environmental Levies? RFF Discussion Papers 1-31.

Boeringer, C. and A. Lange (2005) On the design of optimal grandfathering schemes for emission allowances. European Economic Review 49: P.2041-2055.

Burtraw, D., K. Palmer, R. Bharvirkar and A. Paul (2001) The Effect of Allowance Allocation on the Cost of Carbon Emissions Trading. RFF Discussion Papers 01-30.

Burtraw, D., K. Palmer, R. Bharvirkar and A. Paul (2002) The Effect on Asset Values of the Allocation of Carbon Dioxide Emissions Allowance. The Electricity Journal 15(5): P.5162.

Burtraw, D., K. Palmer and D. Kahn (2005) Allocation of CO2 Emissions Allowances in the Regional Greenhouse Gas Cap-and-Trade Program. RFF Discussion Papers(05-25).

Ellerman, A. D., P. L. Joskow, R. Schmalensee, J. P. Montero and E. M. Bailey (2000). Markets for Clean Air: The U.S. Acid Rain Program, Cambridge University Press.

Entec and NERA (2005). EU Emissions Trading Scheme Benchmark Research for Phase 2. DTI.

Fisher, C. (2001) Rebating Environmental Policy Revenues: Output-Based Allocations and Tradable Performance Standards. (Discussion Paper 01-22).

Harrison, D. J. and D. B. Radov (2002). Evaluation of Alternative Initial Allocation Mechanisms in a European Union Greenhouse Gas Emissions Allowance Trading Schemes. NERA report to DG Environment, European Commission, NERA.

Keats, K. and K. Neuhoff (2005) Allocation of Carbon Emission Certificates in the Power Sector: How generators profit from grandfathered rights. Climate Policy 5: P.61-78.

Montgomery, W. D. (1972) Markets in Licenses and Efficient Control Programs. Journal of Economic Theory 5(3): P.395-418.

Newbery, D. M. G. (2005) Climate change policy and its effect on market power in the gas market. EPRG Working Paper Series 05/10.

Palmer, K. and D. Burtraw (2003) Distribution and Efficiency Consequences of Different Approaches to Allocating Tradable Emission Allowances for Sulphur Dioxide, Nitrogen Oxides and Mercury. Mimeo.

Palmer, K. and D. Burtraw (2004) Electricity, Renewables, and Climate Change: Searching for a Cost-effective Policy. RFF Report.

Sijm, J. P. M., K. Neuhoff and Y. Chen (2006) CO2 cost pass through and windfall profits in the power sector. Climate Policy Forthcoming(Special Issue: Emissions Allocation and Competitiveness in the EU ETS). 